\title{
Severe adverse events following benzathine penicillin $G$ injection for rheumatic heart disease prophylaxis: cardiac compromise more likely than anaphylaxis
}

\author{
Shannon Marantelli, ${ }^{1}$ Robert Hand, ${ }^{2}$ Jonathan Carapetis, ${ }^{2,3}$ Andrea Beaton, ${ }^{4}$ \\ Rosemary Wyber ${ }^{2,5}$
}

'School of Medicine, University of Western Australia, Perth, Western Australia, Australia ${ }^{2}$ Telethon Kids Institute, University of Western Australia, Subiaco, Western Australia, Australia

${ }^{3}$ Department of Infectious Diseases, Perth Children's Hospital, Perth, Western Australia, Australia ${ }^{4}$ Department of Cardiology, Cincinnati Children's Hospital Medical Center, Cincinnati, Ohio, USA

${ }^{5}$ The George Institute for Global Health, Sydney, New South Wales, Australia

\section{Correspondence to} Dr Shannon Marantelli, University of Western Australia, Perth, WA 6009, Australia; shannon.marantelli@health.wa. gov.au

Received 27 February 2019 Revised 13 May 2019 Accepted 23 May 2019
Check for updates

(C) Author(s) (or their employer(s)) 2019. No commercial re-use. See rights and permissions. Published by BMJ.

To cite: Marantelli $S$

Hand R, Carapetis J,

et al. Heart Asia

2019:11:e011191.

doi:10.1136/

heartasia-2019-011191

\section{ABSTRACT}

Objective Secondary prophylaxis through long-term antibiotic administration is essential to prevent the progression of acute rheumatic fever to rheumatic heart disease (RHD). Benzathine penicillin $\mathrm{G}$ (BPG) has been shown to be the most efficacious antibiotic for this purpose; however, adverse events associated with BPG administration have been anecdotally reported. This study therefore aimed to collate case reports of adverse events associated with BPG administration for RHD prophylaxis. Study design A literature review was used to explore reported adverse reactions to BPG and inform development of a case report questionnaire. This questionnaire was circulated through professional networks to solicit retrospective reports of adverse events from treating physicians. Returned surveys were tabulated and thematically analysed. Reactions were assessed using the Brighton Collaboration case definition to identity potential anaphylaxis.

Results We obtained 10 case reports from various locations, with patients ranging in age from early-teens to adults. All patients had clinical or echocardiogramobtained evidence of valvular disease. The majority of patients (80\%) had received BPG prior to the event with no previous adverse reaction. In eight cases, the reaction was fatal; in one case resuscitation was successful and in one case treatment was not required. Only three cases met Level 1 Brighton criteria consistent with anaphylaxis. Conclusion These results indicate that anaphylaxis is not a major cause of adverse reactions to BPG. An alternative mechanism for sudden death following BPG administration in people with severe RHD is proposed.

\section{INTRODUCTION}

Worldwide, 33 million people live with rheumatic heart disease (RHD), the vast majority in developing countries. ${ }^{1}$ The remainder of people with RHD live in vulnerable or indigenous communities worldwide. RHD stems from an abnormal immune reaction to group A streptococcal infection (GAS), precipitating acute rheumatic fever (ARF). Repeated GAS infections cause recurrent ARF episodes in susceptible individuals. These recurrent episodes induce irreversible heart valve damage known as rheumatic heart disease. RHD significantly increases mortality owing to increased incidence of heart failure, arrhythmias, stroke, endocarditis and maternal compromise during pregnancy. ${ }^{2}$

Benzathine penicillin $G$ (BPG) is the mainstay of prevention and treatment of RHD. BPG is formed by the addition of benzathine counterion

\section{Key messages}

What is already known about this subject?

- Rheumatic heart disease (RHD) affects 33 million people worldwide, with affected individuals requiring long-term chemoprophylaxis in the form of monthly benzathine penicillin $\mathrm{G}$ (BPG) injections. There have been anecdotal reports of deaths following BPG administration for many years now.

What does this study add?

- This case series is the first to compile adverse events after BPG administration for secondary prophylaxis of acute rheumatic fever. In compiling these cases, we have developed a new hypothesis for the cause of fatal adverse reactions in children with RHD. We believe that this paper represents a major new approach to understanding why individuals with RHD continue to die after BPG injection.

How might this impact on clinical practice?

- We anticipate that this research will be of interest to clinicians in all countries with a high burden of RHD. If future studies support our hypothesis, it could result in altered management for those with severe valvular disease.

to penicillin sodium creating a molecule with poor aqueous solubility. Intramuscular injections of BPG provide protracted serum penicillin concentration detectable for weeks. ${ }^{34}$ This 'slow release' profile means that BPG can be administered every 2, 3 or 4 weeks to people with a history of ARF to reduce the risk of recurrent GAS infections and ARF episodes. At high levels of adherence this secondary prophylaxis strategy reduces RHD progression and severity. Emerging data suggest that high adherence ( $>80 \%$ of scheduled injections) is associated with reduced mortality from RHD. ${ }^{5}$ Prophylaxis with oral alternatives was found to be less effective at preventing ARF recurrences in all four relevant studies identified in a 2013 systematic review. ${ }^{6}$ Three of these studies also found that oral alternatives were less effective at preventing streptococcal throat infections. ${ }^{6}$ On this basis, the 2010 American Heart Association guidelines for secondary prophylaxis identify provide a grade $1 \mathrm{~A}$ recommendation for four times a week intramuscular BPG relative to 
oral penicillin given two times a day, which is a grade $1 \mathrm{~B}$ recommendation. ${ }^{7}$ Secondary prophylaxis is widely recommended for 10 years after the first episode of ARF. ${ }^{7}$

Anecdotal reports of adverse reactions to BPG have been commonly heard at cardiology conferences for several years, highlighting clinician concern over perceived quality issues. ${ }^{8}$ In 2013, the World Heart Federation surveyed 39 clinicians prescribing BPG: $20 \%$ reported having a patient die from anaphylaxis and $26 \%$ knew of a case of anaphylaxis to BPG causing death. ${ }^{9}$

Serious adverse reactions can have a devastating effect on RHD control programmes. Historically, physician fear of anaphylaxis was found to be one of the major reasons for discontinuation of BPG prophylaxis. ${ }^{10}$ Some states in India have banned BPG injections given concerns about adverse reactions. ${ }^{4}$ In Israel, BPG products have been withdrawn and physicians advised to use alternative medications. ${ }^{11}$ Understanding and addressing these events is imperative to realise the disease altering benefits of secondary prophylaxis for people living with RHD.

Penicillin drugs are one of the most frequent culprits in immune-mediated drug reactions. ${ }^{12}$ However, contemporary data about the prevalence of penicillin allergy are difficult to collect given penicillin allergy is widely over-reported. Idsøe et al undertook a review and reported the frequency of allergic reactions to penicillin occurring between $0.7 \%$ and $10 \% .{ }^{13}$ The rate of anaphylactic reaction was $0.015 \%-0.04 \%$, with fatality occurring in $0.0015 \%-0.002 \%$ of patients. ${ }^{13}$

This study was prompted by anecdotal reports of serious adverse reactions to BPG used for secondary prophylaxis of ARF. Our case series offers a contemporary snapshot of reported events over the last 10 years. We aimed to systematically describe adverse reaction cases, assess potential aetiology of adverse reactions and inform a strategy for responding to these reports.

\section{METHODS}

\section{Literature review}

A semistructured review strategy was used to identify adverse reactions to BPG. Articles were found by searching PubMed with the following search strings:

- ((penicillin)) AND (adverse effect or adverse reaction or anaphylaxis) AND (rheumatic or ARF or RHD)

- ((benzathine penicillin or BPG)) AND (adverse effect or adverse reaction or anaphylaxis)

Additional articles were retrieved from the references of articles originally selected. The search strategy covered publications from 1950 to December 2017. Only articles written in English were considered.

\section{Study design}

The study is a retrospective case series. Approval for the study was obtained from the University of Western Australia Human Research Ethics Committee (\# RA/4/1/7899). Written consent was obtained from each participating physician prior to inclusion in the study.

A questionnaire was sent to clinicians reporting each case, seeking information on patient demographics, details of BPG prophylaxis, description of the adverse event, postevent follow-up and a free text section for additional comments.

Recruitment of adverse event cases began in March 2016 and was completed in April 2017. The sampling strategy was broad based. Colleagues from the professional network of authors JC and RW were contacted to solicit participation. Authors of papers reporting BPG reactions were approached to participate.
Opportunities to contribute to this case series were widely advertised: a call for participants was placed in several editions of RHD Beat (the quarterly newsletter of RHD Action) over the course of the study recruitment period. In addition, the study was discussed at international cardiology meetings in Ethiopia and Mexico.

Participants (clinicians reporting adverse event cases) were sent a study pack, comprising of an information sheet, the consent form and the research questionnaire. All questionnaires that were returned with signed participant consent form were included. Incomplete questionnaires were included, although attempts were made to contact the treating physician via email for additional information. Survey participants were limited to healthcare practitioners who had an RHD patient experience an adverse event following BPG administration for secondary prophylaxis since 2005. Following email engagement with potential participants, study packs were sent to 14 potential participants. Six individual physicians responded providing 10 total cases, for a $43 \%$ response rate.

Returned surveys were tabulated and thematically analysed with key foci collated from the answers. To explore potential aetiology of adverse reactions, each case was assessed against the Brighton Collaboration case definition of anaphylaxis by three authors (SM, RW, RH).${ }^{14}$ Of the numerous anaphylaxis scoring tools, the Brighton Criteria were selected because they were initially developed to assess anaphylactic reactions to immunisation; therefore they were amenable to use in low resource settings and provide an indication of diagnostic certainty in complex scenarios.

The Brighton Criteria identify three features of anaphylaxis required to assess any level of diagnostic certainty: sudden onset, rapidly progressive signs and symptoms and involving multiple $(\geq 2)$ organ systems. ${ }^{14}$ Major and minor criteria are used across four organ systems as outlined in table 1 .

Events are described by level of diagnostic certainty from most certain (Level 1) to least certain (Level 3).

Data were partially deidentified, with year of adverse event removed from the data set. Gender, age and country of the case were preserved for demographic analysis.

\section{RESULTS}

\section{Literature review}

Nineteen reports were identified describing adverse events following BPG administration. Twelve reports pertained to patients receiving BPG for RHD prophylaxis and seven to patients receiving BPG for other indications. A report of adverse reaction to BPG was also identified from pharmacovigilance activities in Zimbabwe. These are reported chronologically to illustrate the changing pattern of adverse reactions over time.

Adverse reactions to BPG injections were first reported in the early 1950s including rash, serum sickness and localised reactions at injection site including pain and swelling. ${ }^{15}$ In 1958 , Hsu and Evans reported a cohort study including systemic adverse reactions in 6 of 32 adults with RHD. The majority of these were cutaneous reactions. One serious, systemic adverse reaction was reported in a 54-year-old woman with advanced valvular RHD. After 18 months of regular BPG injections, the patient collapsed within minutes of routine BPG administration and died. ${ }^{16}$

Steigmann and Suker in 1962 outlined a case series of three fatalities attributed to anaphylactic shock following BPG administration: a 19-year-old man, a 49-year-old man and a woman of unspecified age. ${ }^{17}$ All three patients had RHD with either known cardiac complications or cardiomegaly at autopsy. In 1976, Lue 
Table 1 Brighton criteria for anaphylaxis ${ }^{14}$

\begin{tabular}{|c|c|c|}
\hline Organ systems & Major criteria & Minor criteria \\
\hline $\begin{array}{l}\text { Dermatological or } \\
\text { mucosal }\end{array}$ & $\begin{array}{l}\text { Generalised } \\
\text { urticaria (hives) } \\
\text { or generalised } \\
\text { erythema } \\
\text { Angioedema (not } \\
\text { hereditary), localised } \\
\text { or generalised } \\
\text { Generalised pruritus } \\
\text { with skin rash }\end{array}$ & $\begin{array}{l}\text { Generalised pruritus without } \\
\text { skin rash } \\
\text { Generalised prickle } \\
\text { sensation } \\
\text { Localised injection site } \\
\text { urticarial } \\
\text { Red and itchy eyes }\end{array}$ \\
\hline Cardiovascular & $\begin{array}{l}\text { Measured } \\
\text { hypotension } \\
\text { Clinical diagnosis } \\
\text { of uncompensated } \\
\text { shock indicated by } \\
\text { at least three of the } \\
\text { following: } \\
\text { - Tachycardia } \\
\text { - Capillary refill } \\
>3 \mathrm{~s} \\
\text { - Reduced central } \\
\text { pulse volume } \\
\text { - Decrease level } \\
\text { or loss of } \\
\text { consciousness }\end{array}$ & $\begin{array}{l}\text { Reduced peripheral } \\
\text { circulation as indicted by } \\
\text { the combination of at least } \\
\text { two of: } \\
\text { - Tachycardia } \\
\text { - A capillary refill time of } \\
>3 \mathrm{~s} \text { without hypotension } \\
\text { - A decreased level of } \\
\text { consciousness }\end{array}$ \\
\hline Respiratory & $\begin{array}{l}\text { Bilateral wheeze } \\
\text { (bronchospasm) } \\
\text { Stridor } \\
\text { Upper airway } \\
\text { swelling (lip, tongue, } \\
\text { throat, uvula or } \\
\text { larynx) } \\
\text { Respiratory distress, } \\
\text { defined by two } \\
\text { or more of the } \\
\text { following: } \\
\text { - Tachypnoea } \\
\text { - Increased use } \\
\quad \text { of respiratory } \\
\quad \text { muscles } \\
\text { - Recession } \\
\text { - Cyanosis } \\
\text { - Grunting }\end{array}$ & $\begin{array}{l}\text { Persistent dry cough } \\
\text { Hoarse voice } \\
\text { Difficulty breathing without } \\
\text { wheeze or stridor } \\
\text { Sensation of throat closure } \\
\text { Sneezing, rhinorrhoea }\end{array}$ \\
\hline Gastrointestinal & & $\begin{array}{l}\text { Diarrhoea } \\
\text { Abdominal pain } \\
\text { Nausea } \\
\text { Vomiting }\end{array}$ \\
\hline Laboratory & & $\begin{array}{l}\text { Mast cell tryptase elevation } \\
\text { > upper normal limit }\end{array}$ \\
\hline
\end{tabular}

et al reported seven allergic reactions (one delayed type reaction, four serum sickness reactions and two anaphylactic reactions) in 105 patients with ARF or RHD. ${ }^{10}$ Demographics and outcomes for the patients who suffered anaphylactic reaction were not reported.

The only large-scale study to date was a prospective study carried out in 1991 by the International Rheumatic Fever Study Group. ${ }^{18}$ A total 1790 patients were enrolled over 1988-1990, an equivalent period of 2736 patient years. A total of 32430 injections were given. Allergic reaction following BPG administration was reported in 57 of 1790 patients. Four episodes of anaphylactic reactions occurred; three of these people recorded as having anaphylaxis were being actively treated for cardiac failure. Three recovered and one died: a 15 -year-old girl with severe mitral valve disease and chronic congestive cardiac failure who died 6 days after injection. From this study, the rate of allergic reaction to BPG was estimated at 3.2\%, with anaphylaxis estimated at $0.2 \%$. The frequency of anaphylactic reaction was calculated at 1.23 per 10000 injections. ${ }^{19}$

Sporadic reports of other adverse reactions were identified in published literature. In 2000, a WHO Drug Information Bulletin reported the deaths of two male patients in Zimbabwe, aged 10 and 14 years, both following BPG administration for RHD. ${ }^{20}$ Regmi and Upadhyaya in Nepal reported 65 patients with allergic reactions, including 5 anaphylactic reactions, in over 4700 patients in $2011 .^{21}$ There were no reported fatalities in this study. In 2014, a Turkish group reported suspected allergic reaction in 11 of 535 children, although following further testing all skin prick tests were negative and only one provocation test was positive. ${ }^{22}$ In Nigeria, an 11-year-old girl was successfully resuscitated following reported anaphylaxis after BPG for RHD; while in India a 40-year-old woman died. ${ }^{23}{ }^{24}$ Two deaths were also reported in young people receiving BPG for secondary prophylaxis of rheumatic fever in Switzerland/Israel. Both patients were male (aged 10 and 12 years) with severe mitral valve disease. ${ }^{11}$

These studies and their reported reaction rates, as well as any fatalities, are summarised in table 2. Estimates for the rate of allergic reaction to BPG in patients with RHD range widely, from $1.21 \%{ }^{15}-18.7 \%,{ }^{16}$ and $0.12 \%{ }^{21}-3.1 \%{ }^{16}$ for anaphylactic reaction. A total of 157 allergic reactions were reported, for an overall rate of $2 \%$. Total 21 anaphylactic reactions and 10 fatalities were reported, for a rate of $0.27 \%$.

\section{Cases}

We received 11 completed physician questionnaires comprising 11 individual cases. One case was excluded because BPG was administered during an unrelated surgical procedure, not for prophylaxis of RHD.

\section{Case 1 (Female, 12, Timor-Leste)}

A 12-year-old woman with valvular heart disease: Valve disease was reported as severe aortic and mitral regurgitation with 'intractable heart failure'. The patient had not previously received any BPG injection. She had no history of adverse reactions to any other medicine. Powered BPG was mixed with an unspecified volume of water for injection and administered into the dorsogluteal muscle at a tertiary hospital. Immediately following the injection, the patient experienced 'shock and wheeze'. Within half an hour, she developed hypertension and severe dyspnoea. She was treated with epinephrine, intravenous fluids, oxygen and steroids. The patient died within 2 hours of BPG administration.

Brighton Criteria: Level 2 (one major cardiovascular AND one major respiratory criterion)

\section{Case 2 (Female, 12, India)}

A 12-year-old woman with valvular heart disease: Valve disease was reported as severe mitral stenosis. The patient had been receiving BPG for 8 months, without any evidence of adverse reactions to BPG. Details of adverse reaction to any other medication were unavailable. Powered BPG was administered into the dorsogluteal muscle at a private clinic. The diluent used was not known to the respondent. Within2-3 min, the patient had collapsed and died. Details regarding clinical symptoms and attempted treatment and attempted resuscitation are not available for this case. data 
Table 2 Allergic and anaphylactic reactions following BPG administration for RHD prophylaxis

\begin{tabular}{|c|c|c|c|c|c|c|c|}
\hline \multirow[b]{2}{*}{ Study } & \multirow[b]{2}{*}{ Year } & \multirow[b]{2}{*}{ Demographics } & \multicolumn{2}{|l|}{ Allergic reactions } & \multicolumn{2}{|c|}{ Anaphylactic reactions } & \multirow[b]{2}{*}{ Fatalities } \\
\hline & & & $\begin{array}{l}\text { Number of events } \\
\text { (total patients) }\end{array}$ & $\%$ & $\begin{array}{l}\text { Number of events } \\
\text { (total patients) }\end{array}$ & $\%$ & \\
\hline Stollerman et $a l^{15}$ & 1952 & Children (6-14 years) & $4(135)$ & 3.0 & $0(135)$ & 0 & 0 \\
\hline Stollerman et $a l^{15}$ & 1955 & Children (6-16 years) & $5(410)$ & 1.2 & $0(410)$ & 0 & 0 \\
\hline Hsu and Evans ${ }^{16}$ & 1958 & Adults (20-54 years) & $6(32)$ & 18.7 & $1(32)$ & 3.1 & 1 \\
\hline Lue et $a l^{10}$ & 1976 & Children (age not specified) & $7(105)$ & 6.7 & $2(105)$ & 1.9 & $N / R$ \\
\hline Markowitz and Lue $\mathrm{e}^{39}$ & 1991 & Children and adults ( $5-28$ years) & $57(1792)$ & 3.2 & $4(1792)$ & 0.2 & 1 \\
\hline $\mathrm{WHO}^{44}$ & 2000 & Children (10-14 years) & $\mathrm{N} / \mathrm{A}$ & N/A & $2(2)$ & 100 & 2 \\
\hline Regmi and Upadhyaya ${ }^{21}$ & 2011 & Children and adults (age not specified) & $65(4712)$ & 1.4 & $5(4712)$ & 0.1 & 0 \\
\hline Kaya et $a l^{22}$ & 2014 & Children (5-16 years) & $11(535)$ & 2.1 & $0(535)$ & 0 & 0 \\
\hline
\end{tabular}

BPG, benzathine penicillin G; N/R, not reported; RHD, rheumatic heart disease.

\section{Case 3 (Male, 13, Egypt)}

A 13-year-old man with valvular heart disease: Valve disease reported as with mild-moderate mitral regurgitation and tricuspid regurgitation of unspecified severity. This patient had been receiving BPG for 5 years. He had two previous (unspecified) reactions to BPG injections. BPG injections were ceased for 3 months following reaction and then resumed. The patient had no history of reaction to any other medication. Powdered BPG mixed with sterile water was administered into the dorsogluteal muscle at a pharmacy. Immediately following administration of BPG, the patient developed syncope with peripheral cyanosis. No treatment was administered. The patient experienced lethargy for the next 2 days before reporting a full recovery. $\mathrm{He}$ continues to receive BPG injections.

Brighton Criteria: Did not meet criteria for likely anaphylaxis

\section{Case 4 (Female, 15, Uganda)}

A 15-year-old woman with valvular heart disease: Valve disease was reported as severe, with severe mitral regurgitation (jet length $=8.4 \mathrm{~cm}$ ) and moderate tricuspid regurgitation (pressure gradient $80 \mathrm{~mm} \mathrm{Hg}$, reflecting likely $3 / 4$ systemic pulmonary artery pressure). The patient had received BPG for 11 months at the time of the adverse event, with no previous adverse reaction to either BPG or any other medication. Powdered BPG was mixed with water for injection $(10 \mathrm{~mL})$ and lidocaine $(2$ $\mathrm{mL}$ ) and then injected into the dorsogluteal muscle at a regional hospital. Immediately following injection, the patient experienced syncope, bradycardia and apnoea, as well as clinically unconfirmed hypotension. She was treated with epinephrine, steroids, ventilation and atropine. Cardiopulmonary resuscitation (CPR) was administered for $30 \mathrm{~min}$ however the patient deceased.

Free text information provided by the treating physician stated the patient felt unwell the day of injection. The treating physician obtained collateral history from the patient's mother who stated 'had not voided urine in the 3 days' before BPG injection. The treating physician commented 'it is possible that she was in early stage renal failure'.

Brighton Criteria: Did not meet criteria for likely anaphylaxis
Case 5 (Female, 16, Nepal)

A 16-year-old woman with valvular disease: The severity or nature of heart valve disease was not described. The patient had been receiving BPG for 7 years at the time of the adverse event with no previous adverse reaction to BPG or any other medication. The reporting physician volunteered that her previous skin prick test was negative. Powdered BPG was mixed with sterile water and injected into the dorsogluteal muscle at a regional hospital. Within an hour of administration of BPG, the patient experienced giddiness, itching and skin rash, followed by hypotension and dyspnoea. She was treated with epinephrine, atropine, steroids, antihistamines and oxygen and died on the day of BPG injection.

Brighton Criteria: Level 1 (one major dermatological AND one major cardiovascular AND one major respiratory criterion)

Case 6 (Male, 17, Uganda)

A 17-year-old man with valvular heart disease: Valve disease was reported as severe aortic insufficiency, mild mitral stenosis, severe mitral regurgitation (jet length $8.3 \mathrm{~cm}$ ) and severe tricuspid regurgitation. The patient had been receiving BPG for 7 months, with no previous adverse reaction to either BPG or other medication. Powdered BPG was mixed with sterile water $(10 \mathrm{~mL})$ and lidocaine $(2 \mathrm{~mL})$ and administered into the dorsogluteal muscle at a regional hospital. Immediately following administration, the patient experienced 'dizziness and hypotension'. He was treated with epinephrine, hydrocortisone, lignocaine, dextrose, intravenous fluids and oxygen. CPR was terminated after 1 hour and the patient deceased.

Brighton Criteria: Uncertain —unable to assess due to missing data

\section{Case 7 (Female, 19, Nepal)}

A 19-year-old woman with known valvular disease: The severity of valve disease was not reported. The patient had had been receiving BPG for the past 6 months with no previous adverse reaction to BPG or any other medications. The reporting clinician volunteered that the patient had had a previous a negative skin test for penicillin allergy. Powdered BPG was mixed with sterile water and administered into the dorsogluteal muscle at 
a regional hospital. Within an hour of administration of BPG, the patient experienced giddiness, itching, dyspnoea and hypotension. She was treated with epinephrine, atropine, steroids, antihistamines and oxygen. She fully recovered from this event and was switched to oral prophylaxis with erythromycin.

Brighton Criteria: Level 2 (one minor dermatological AND one major cardiovascular AND one major respiratory criterion)

\section{Case 8 (Female, 24, Nepal)}

A 24-year-old woman with valvular disease: The severity of valve disease was not reported. She had been receiving BPG for 5 years with no previous adverse reaction to BPG or any other medications. The reporting clinician volunteered that the patient had had previous a negative skin test for penicillin allergy. Powdered BPG was mixed with sterile water and administered into the dorsogluteal muscle at a tertiary hospital. Within 1 hour of following administration of BPG, the patient experienced giddiness, itching and skin rash, followed by hypotension and dyspnoea. She was treated with epinephrine, atropine, steroids, antihistamines and oxygen, but died that day.

Brighton Criteria: Level 1 (one major dermatological AND one major cardiovascular AND one major respiratory criterion)

\section{Case 9 (Male, 32, Uganda)}

A 32-year-old man with valvular disease: The severity of valve disease was not reported. He had been receiving BPG secondary prophylaxis for 3 years with no previous adverse reaction to BPG or any other medications. Powdered BPG was mixed with sterile water and administered into the dorsogluteal muscle in a tertiary hospital. Within $5 \mathrm{~min}$ of injection the patient developed 'sudden drop of blood pressure, cessation of breathing and loss of consciousness'. Epinephrine, promethazine and intravenous fluids were immediately given. Treatment was escalated to Advanced Life Support (not further described by respondent). The patient failed to respond after 1 hour and died on the day of BPG administration.

Brighton Criteria: Uncertain —unable to assess due to missing data

\section{Case 10 (Male, 35, Nepal)}

A 35-year-old man with valvular heart disease: The severity of valve disease was not reported. He had been receiving BPG prophylaxis for 10 years at the time of reaction and had not had any previous reactions to BPG or other medications. He had a previous negative skin prick test. Powdered BPG, mixed with sterile water, was administered into the dorsogluteal muscle. Less than 1 hour following administration of BPG, the patient experienced giddiness, shortness of breath, itching and rash, followed by tachycardia, respiratory distress and hypotension. He was given epinephrine, steroids, antihistamine, oxygen and ventilated, but died that day.

Brighton Criteria: Level 1 (one major dermatological AND one major cardiovascular AND one major respiratory criterion)

\section{Comparison of cases}

The characteristics and outcome of the adverse reactions in the 10 cases that we received are summarised in table 3 .

\section{DISCUSSION}

This case series confirms that fatal events following BPG injections occur in the setting of ARF prophylaxis. Previous reports were largely anecdotal, reported by clinicians at conferences and meetings. This structured survey of clinicians has improved these descriptions and facilitated preliminary analysis of potential causes. However, eliciting accurate descriptions of traumatic events in low-resource settings is challenging. Incomplete documentation made it difficult to address the strict criteria for anaphylaxis described by the Brighton criteria. It remains unclear as to the exact cause of death in several individuals. We explore four hypotheses to explain the deaths.

The first hypothesis is that these deaths are anaphylactic reactions. In all cases, the adverse event occurred within 1 hour of BPG administration, consistent with the core definition of anaphylaxis as having 'rapid onset'. ${ }^{14}$ A number of the cases had evidence of cardiovascular and respiratory compromise; however, only three of our cases reported dermatological symptoms, which are needed to meet Level 1 Brighton criteria for anaphylaxis. ${ }^{14}$ The Level 1 cases in this case series probably reflect true anaphylaxis, although it is notable that all of these cases occurred in Nepal. Two cases met only Level 2 diagnostic certainty indicating a less clear classification of anaphylaxis. Two cases were unlikely to be anaphylactic in nature and three cases lacked sufficient data for classification.

Of the non-fatal reaction in this case series, one patient had a potential anaphylactic reaction (Case 7, Brighton Level 2) and responded to treatment for anaphylaxis, including epinephrine. This has some similarities to an event in Nigeria; an 11-year-old

\begin{tabular}{|c|c|c|c|c|c|c|c|}
\hline Case & Case demographics & Valvular disease & Prior ADR to BPG & Type of BPG administered & Time to adverse event & Brighton criteria & Outcome \\
\hline 1 & $\begin{array}{l}\text { Female, 12, } \\
\text { Timor Leste }\end{array}$ & Yes & No* & Powdered & Immediate & Level 2 & Death \\
\hline 2 & Female, 12, India & Yes & No & Powdered & Immediate & Uncertaint & Death \\
\hline 3 & $\begin{array}{l}\text { Male, 13, } \\
\text { Egypt }\end{array}$ & Yes & Yes & Powdered & Immediate & $\begin{array}{l}\text { Did not meet } \\
\text { criteria }\end{array}$ & Full recovery \\
\hline 5 & Female, 16, Nepal & Yes & No & Powdered & $<1$ hour & Level 1 & Death \\
\hline 6 & Male, 17, Uganda & Yes & No & Powdered & Immediate & Uncertaint & Death \\
\hline 7 & Female, 19, Nepal & Yes & No & Powdered & $<1$ hour & Level 2 & Full Recovery \\
\hline 8 & Female, 24, Nepal & Yes & No & Powdered & $<1$ hour & Level 1 & Death \\
\hline 9 & Male, 32, Uganda & Yes & No & Powdered & Immediate & Uncertaint & Death \\
\hline
\end{tabular}

*First dose of BPG

tUnable to assess due to missing data.

$A D R$, adverse drug reaction; $B P G$, benzathine penicillin $G$. 
woman who collapsed after her third dose of BPG with symptoms considered anaphylactic by treating doctors. She was resuscitated with epinephrine and other medical therapy. ${ }^{24} \mathrm{We}$ were unable to contact the medical staff involved in this case for inclusion in this case series. In this series, eight of nine patients where management was clearly described received epinephrine, although the dosage was not disclosed. Given the anaphylactic potential of BPG, all healthcare providers administering the product should have training on identifying and managing anaphylaxis. ${ }^{25}$

The second hypothesis is that problems with BPG products are causing adverse reactions. Two main forms of BPG exist: a low cost lyophilised powder available in many brands and a high cost cold chain dependent suspension produced by Pfizer alone. ${ }^{4}$ All adverse events occurred following administration of powdered BPG which are reconstituted in sterile water+/-10ignocaine. Concerns have previously been raised regarding the quality and efficacy of powdered BPG, the variability between different formulations and the lack of contemporary monographs for the product. ${ }^{26}$ Early studies demonstrated that purer penicillins are more potent and less toxic (Welch et al, 1944, cited in Guthe et al, 1958). ${ }^{27}$ More recent studies have shown that different brands of powdered BPG have altered physical characteristics including crystal shape and differences in solubility, both affecting the rates of needle blockage. ${ }^{28}{ }^{29}$ Additionally, Kassem et al (1996) showed a significant pharmacokinetic difference between two brands of powdered BPG, without clear explanation. ${ }^{30}$

The British pharmacopoeia outlines the required concentrations of benzathine and penicillin $G$ required for a product to be sold as BPG. Manufacturers are additionally required to produce medication according to Good Manufacturing Practice (GMP), although there have been regulatory concerns about GMP compliance by at least one manufacturer. ${ }^{31}$ Given the hydrophobic characteristics of BPG, emulsifying agents are often added to improve the solubility including soy lecithin. Barni $e t$ al (2015) reported on an 11-year-old girl who had an adverse drug reaction (ADR) to BPG injection after a change from lyophilised powder to prefilled syringe suspension. Subsequent testing revealed negative response to penicillins, but was positive to soy, highlighting additives as a potential cause of ADRs. ${ }^{32}$

While it is possible that serious adverse reactions could be caused by impurities or contamination of some BPG products, empiric evidence does not support this. Work is currently underway to assess for potency and breakdown compounds known to cause anaphylactic reactions at the authors' institution. Preliminary testing has not identified any evidence of product impurities. ${ }^{33}$ Diluents from source countries have not been tested and could represent an occult source of contamination. It is also possible that contamination of BPG vials could occur at the point of use, particularly if the 2.4 MIU vials results are used for two patients (1.2 MIU each) resulting in a 'double stab' of the phial and introduction of contaminants. This is the proposed mechanism of recent delayed adverse reactions in Ghana. ${ }^{34}$ More information about products and procedures used in BPG administration is needed to assess the possibility of contamination as a cause for these events.

The third hypothesis is that the administration technique of BPG injections is causing adverse reactions. Inadvertent intravascular administration of BPG could cause collapse and sudden death. A review of non-allergic adverse reactions to BPG injections identified 45 events of likely accidental intra-arterial administration causing a variety of systemic symptoms. ${ }^{29}$ Adverse outcomes, including cardiac arrest, were attributed to the formation of emboli after injection. Intra-arterial administration is particularly well described in a case from America which was associated with life-threatening pulmonary odema. ${ }^{35}$ All cases in this series received dorsogluteal injections. Vascular structures can be found near the dorsogluteal muscle where injections are commonly administered. ${ }^{35}$ Injection in the ventrogluteal site may be associated with reduced risk of intravascular administration but is not widely practiced, except in Australia where it is recommended in some training materials. ${ }^{36}$ Irrespective of site, steps to reduce the risk of intravascular administration should be taken, including training of healthcare staff on safe injection technique.

In 2 of these 10 cases the local anaesthetic lignocaine was added to diluents prior to administration. This is intended to reduce the pain of administration and is standard practice in some settings. ${ }^{37}$ The use of local anaesthetic raises the possibility of local anaesthetic toxicity, particularly with inadvertent intravascular administration. However, given the small volumes of local anaesthetic reportedly used, this seems well below accepted thresholds for systemic toxicity. ${ }^{37}$ Systemic serious allergy to lignocaine is also very rare. The volume of diluent used for injection was not specifically requested on the survey. In Case 4 , the respondent volunteered that $12 \mathrm{~mL}(10 \mathrm{~mL}$ water $+2 \mathrm{~mL}$ of lignocaine) was administered during intramuscular injection. This large volume exceeds suggested maximum injection size, potentially increasing pain and the risk of tissue damage. ${ }^{38}$

The final, and we believe most likely, hypothesis is that the underlying structural cardiac disease itself predisposes to adverse outcomes. In this series all patients were described as having valvular disease. Participants were asked: 'did the patient have valvular disease based on auscultation or echocardiography'-and were asked to 'specify the nature and severity of valve lesions if known'. In four cases, this was reported to be severe, consistent with existing case reports of death following BPG injection. ${ }^{18} 23$ This study did not identify any cases of adverse events or fatalities in subclinical patients detected on echo screening despite substantial populations of children with latent RHD receiving secondary prophylaxis injections in some countries or in cases on secondary prophylaxis following ARF without RHD. If any of the above three hypotheses was true, severe reactions should be as likely in cases without RHD as those with RHD. Pre-existing cardiac disease may be associated with systemic adverse reactions and contribute to an impaired response to resuscitation. ${ }^{39}$ In particular, it is well established that mitral valve disease is a risk factor for arrhythmias and sudden cardiac death. ${ }^{40}$ Pain or fear of BPG administration could drive a physiological response precipitating decompensation or arrhythmic events. Vasovagal hypotension/syncope, a well-described response to intramuscular injection, could also contribute, particularly in patients with severe valvular disease resulting in inadequate compensatory mechanisms. Case 4 presents extra evidence for this hypothesis with reported bradycardia at the time of adverse event-whereas an anaphylactic patient would be tachycardic. Additionally, only one of the reported cases (Case 7) responded to epinephrine treatment of anaphylaxis and many were reported as being very sudden without the characteristic organ system manifestations of anaphylaxis. A plausible physiological pathway for this mechanism is postulated in figure 1.

The hypothesis of heart involvement is supported by the relatively few adverse outcomes in otherwise healthy people receiving BPG for other indications. A systematic review by Galvao et al assessed the safety of BPG for the treatment of syphilis in pregnant women. Their pooled results showed three cases 


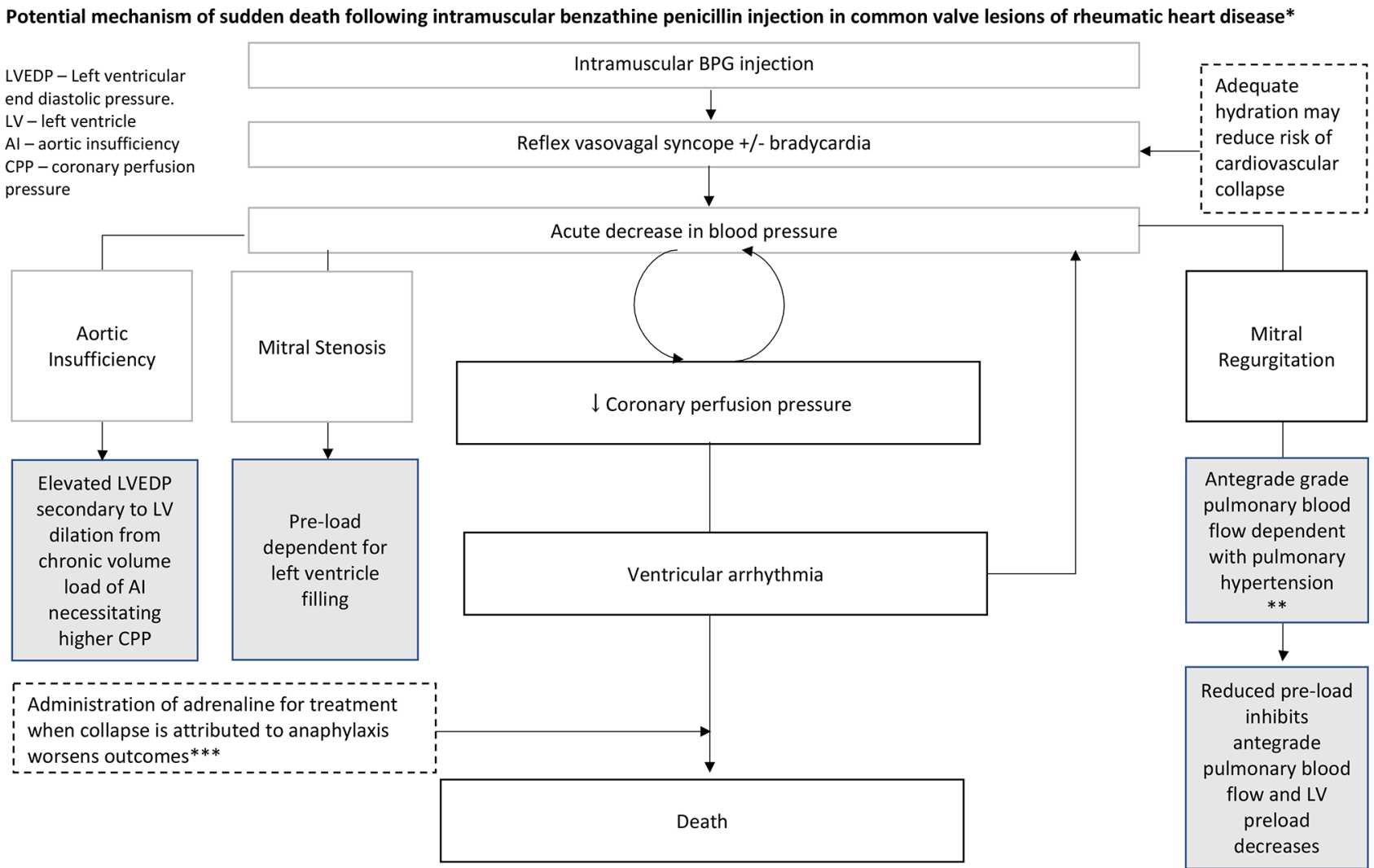

Figure 1 Potential mechanism of sudden death following intramuscular benzathine penicillin injection in common valve lesions of rheumatic heart disease. * Grey boxes reflect contributory or predisposing characteristics of valve lesions. Dashed boxes indicate other potential contributing/ mitigating factors. *Plausible mechanism in cases 2, 4, 6 and 9 of this case series based on: very rapid onset, no respiratory or skin symptoms and no positive response to epinephrine. †Described in case 4 and potentially case 6 . ‡Documented. BPG, benzathine penicillin $\mathrm{G}$.

of anaphylaxis in 20353 patients receiving BPG for non-RHD indications, with only one fatality. Patients with a diagnosis of rheumatic fever were more likely to have anaphylaxis $(n=7)$ or death $(n=2)$ from a total of 1822 patients. ${ }^{19}$ An increased risk of sudden death could also be expected for people with severe RHD following other medical intervention or injection. A brief review of the literature has identified one report sharing similarities with some of our cases but unrelated to BPG. ${ }^{41}$ The association between severe heart valve disease and sudden death following BPG injection warrants more detailed study in a setting where echocardiography results are readily available.

Quantifying and understanding adverse reactions to BPG is a global challenge. In this study, only cases from Nepal and Uganda were reported to national pharmacovigilance programme. The treating physician from Case 1 noted that Timor-Leste does not have a national pharmacovigilance programme. In practice, very few developing countries have mechanisms for reporting ADRs. ${ }^{42}$ This illustrates the difficulties in collecting and interpreting adverse reactions to BPG through standard mechanisms.

This case series has several limitations. First, we had no fixed geographic boundaries or exhaustive sampling. Therefore, it is not possible to calculate adverse reaction incidence. The absolute sample size is relatively small. As this was a retrospective case series, it is at risk of recall bias and missing data. While some clinicians had access to the original patient notes, some reported their recall of events. Respondents were not asked whether they had access to clinical notes as part of the survey, although it is clear some did because they quoted notes verbatim in their free text responses. However, it is impossible to be sure what proportion of respondents had access to the notes. In addition, 3 of the 10 surveys were not fully completed. A degree of selection bias is also likely-with physicians who had experienced a negative outcome being more likely to participate than those with experience of non-fatal systemic adverse reactions. Design of the questionnaire for participants was exploratory and did not mandate responses to all questions. In particular, dermatological responses to fulfil the Brighton Criteria may not have been fully elicited. The severity of heart valve disease was inconsistently reported. This reflects access to echocardiography in developed settings but makes it difficult to fully contextualise results.

Although it is not possible to calculate an incidence of systemic adverse reactions to BPG from these data, the identification of 10 serious adverse events is worrying relative to historic data (table 1). The authors of this paper have also been contacted by clinical colleagues to discuss deaths associated with BPG in four other countries since data collection for this study finished.

The cases presented here suggest that many severe episodes recorded or considered by treating clinicians as anaphylaxis may in fact be a mimic. Instead, we have potentially uncovered a different syndrome, whereby individuals with severe valvular disease may develop severe, sometimes fatal, compromise in response to receiving BPG injections. Should this be proven, the implications would be profound. First, providers and clients should be reassured that anaphylaxis remains a very rare complication of penicillin administration and hopefully given confidence in the existing medication supply. Second, the approach to administration of secondary prophylaxis in individuals with documented severe RHD may need rethinking. A prospective study to explore ADRs to BPG is needed to better understand the variable determinants of reactions, and in the meantime 
Box 1 Recommendations for BPG administration for

rheumatic heart disease

- Benzathine penicillin G (BPG) injections should be administered by people trained in intramuscular injections and identification of anatomical landmarks which minimise the risk of intravascular administration.

- Efforts should be made to reduce the pain of BPG injections, particularly in people with advanced heart valve disease.

- The smallest possible volume of diluent should be used when reconstituting BPG.

- BPG injections should only administered by people trained in diagnosis and management of anaphylaxis.

- Adrenaline (Epinephrine) should always be available (ideally in appropriately dosed prefilled syringes) when BPG injections are delivered.

- Adverse reactions to BPG should be reported to national pharmacovigilance programmes where they exist.

- All secondary prophylaxis programmes should have a mechanism for reporting ADRs to BPG.

- A contemporary drug monograph for BPG is needed to specify acceptable parameters of injection volume, particle size, syringability and consistency. There should be a mechanism for clinicians with concerns about particular batches to have products tested against this monograph.

- Ultimately, a reformulated form of BPG which is less painful and administered less frequently could reduce the impact of these adverse events and improve adherence with secondary prophylaxis.

practical recommendations are needed. We outline a set of pragmatic recommendations in box 1 .

Contributors SM, JC and RW were involved in study design and methodology. SM and RW were involved in data curation. SM, RH and RW were involved in formal analysis. SM and RW were involved in drafting the initial manuscript. SM, RH, JC, AB and RW were involved in reviewing the manuscript for publication.

Funding The authors have not declared a specific grant for this research from any funding agency in the public, commercial or not-for-profit sectors.

Competing interests None declared.

Patient consent for publication Not required.

Ethics approval University of Western Australia Human Research Ethics Committee (\# RA/4/1/7899).

Provenance and peer review Not commissioned; externally peer reviewed.

Data availability statement Data are available on reasonable request.

\section{REFERENCES}

1. Watkins DA, Johnson CO, Colquhoun SM, et al. Global, regional, and national burden of rheumatic heart disease, 1990-2015. N Engl J Med Overseas Ed 2017;377:713-22.

2. Carapetis JR, McDonald M, Wilson NJ. Acute rheumatic fever. Lancet 2005;366:155-68.

3. Hand RM, Salman S, Newall N, et al. A population pharmacokinetic study of benzathine benzylpenicillin $\mathrm{G}$ administration in children and adolescents with rheumatic heart disease: new insights for improved secondary prophylaxis strategies. J Antimicrob Chemother 2019;366.

4. Wyber R. Global status of BPG report, 2016. Available: https://rhdaction.org/sites/ default/files/RHD\%20Action_Global\%20Status\%20of\%20BPG\%20Report_Online\% 20Version.pdf [Accessed 20 Sep 2017].

5. Okello $\mathrm{E}$, Longenecker $\mathrm{CT}$, Beaton $\mathrm{A}$, et al. Rheumatic heart disease in Uganda: predictors of morbidity and mortality one year after presentation. BMC CardiovasC Disord 2017;17

6. Manyemba J, Mayosi BM. Intramuscular penicillin is more effective than oral penicillin in secondary prevention of rheumatic fever--a systematic review. S Afr Med J 2003:93:212-8
7. Gerber MA, Baltimore RS, Eaton $C B$, et al. Prevention of rheumatic fever and diagnosis and treatment of acute streptococcal pharyngitis: a scientific statement from the American Heart Association rheumatic fever, endocarditis, and Kawasaki disease Committee of the Council on cardiovascular disease in the young, the interdisciplinary Council on functional genomics and translational biology, and the interdisciplinary Council on quality of care and outcomes research: endorsed by the American Academy of pediatrics. Circulation 2009;119:1541-51.

8. Wyber R, Boyd BJ, Colquhoun $\mathrm{S}$, et al. Preliminary consultation on preferred product characteristics of benzathine penicillin $\mathrm{G}$ for secondary prophylaxis of rheumatic fever. Drug Deliv Transl Res 2016;6:572-8.

9. Taubert K, Marko SB. Access to essential medicines: illuminating disparities in the global supply of benzathine penicillin $\mathrm{G}$ in the context of rheumatic fever/rheumatic heart disease prevention. J Am Coll Cardiol 2013;61.

10. Lue HC, Chen CL, Wei H. Some problems in long-term prevention of streptococcal infection among children with rheumatic heart disease in Taiwan. Jpn Heart J 1976;17:550-9.

11. Berkovitch M, Ashkenazi-Hoffnung L, Youngster I, et al. Fatal and near-fatal nonallergic reactions in patients with underlying cardiac disease receiving benzathine penicillin G in Israel and Switzerland. Front Pharmacol 2017;8.

12. Solensky R. Allergy to $\beta$-lactam antibiotics. J Allergy Clin Immunol 2012;130:1442-1442.e5.

13. Idsoe $\mathrm{O}$, Guthe T, Willcox RR, et al. Nature and extent of penicillin side-reactions, with particular reference to fatalities from anaphylactic shock. Bull World Health Organ 1968;38:159-88.

14. Rüggeberg JU, Gold MS, Bayas J-M, et al. Anaphylaxis: case definition and guidelines for data collection, analysis, and presentation of immunization safety data. Vaccine 2007;25:5675-84.

15. Stollerman GH, Rusoff JH, Hirschfeld I. Prophylaxis against group A streptococci in rheumatic fever; the use of single monthly injections of benzathine penicillin G. N Engl J Med 1955;252:787-92.

16. Hsu I, Evans JM. Untoward reactions to benzathine penicillin $G$ in a study of rheumatic-fever prophylaxis in adults. N Engl J Med 1958;259:581-3.

17. Steigmann F, Suker FR. Fatal reactions to benzathine penicillin $\mathrm{G}$. report of three cases and discussion of contributory factors. JAMA 1962;179:288-90.

18. Allergic reactions to long-term benzathine penicillin prophylaxis for rheumatic fever Lancet 1991;337:1308-10.

19. Galvao TF, Silva MT, Serruya SJ, et al. Safety of benzathine penicillin for preventing congenital syphilis: a systematic review. PLoS One 2013;8:e56463.

20. Organization WH. WHO pharmaceuticals Newsletter 2000, No. 04. Geneva, Switzerland; 2000.

21. Regmi PR, Upadhyaya AB. Allergic reaction to long - term benzathine penicillin injection for secondary prevention of acute rheumatic fever and recommendations for skin testing. Nepal Heart J 2011;8:16-18.

22. Kaya $A$, Erkoçoğlu $M$, Şenkon $O G$, et al. Confirmed penicillin allergy among patients receiving benzathine penicillin prophylaxis for acute rheumatic fever. Allergol Immunopathol 2014;42:289-92.

23. Kalani PN, Makwana HD, Patel KP, et al. A fatal anaphylactic reaction followed by Inj. benzathine penicillin: a case report. Indian J Foren Med Toxicol 2016;10.

24. Sani UM, Ahmed H, Jiya NM. Pattern of acquired heart diseases among children seen in Sokoto, North-Western Nigeria. Niger J Clin Pract 2015;18:718-25.

25. Simons FER, Ardusso LRF, Bilò MB, et al. World allergy organization guidelines for the assessment and management of anaphylaxis. World Allergy Organ J 2011;4:13-37.

26. Wyber R, Taubert $K$, Marko $S$, et al. Benzathine penicillin $G$ for the management of RhD: concerns about quality and access, and opportunities for intervention and improvement. Glob Heart 2013;8:227-34.

27. Guthe T, Idsoe 0, Willcox RR, et al. Untoward penicillin reactions.. Bull World Health Organ 1958;19:427-501.

28. Chen RY, L; Liu M. Analysis of crystal properties and pumping needle experiment of 2 kinds of benzathine benzylpenicillin. China Pharmacy 2013;24:784-6.

29. Zaher SK, Abou-Shleib AS, El-Kholy H, et al. Differences in serum penicillin concentrations following intramuscular injection of benzathine penicillin $G(B P G)$ from different manufacturers. J Pharma Med 1992;2:17-23.

30. Kassem AS, Zaher SR, Abou Shleib $H$, et al. Rheumatic fever prophylaxis using benzathine penicillin $\mathrm{G}(\mathrm{BPG})$ : two- week versus four-week regimens: comparison of two brands of BPG. Pediatrics 1996;97:992-5.

31. Nurse-Findlay S, Taylor MM, Savage M, et al. Shortages of benzathine penicillin for prevention of mother-to-child transmission of syphilis: an evaluation from multicountry surveys and stakeholder interviews. PLoS Med 2017;14:e1002473.

32. Barni S, Mori F, Pantano $S$, et al. Adverse reaction to benzathine benzylpenicillin due to soy allergy: a case report. J Med Case Rep 2015;9.

33. Hand RM, Senarathna G, Page-Sharp M, et al. P0646 benzathine penicillin G quality and potency - do we need a new manufacturing standard? Glob Heart 2018;13.

34. Adogla-Bessa D. Serious adverse reaction reports, new Senchi health centre. Akrade 2018.

35. Lelubre C, Lheureux PER, Lheure P. Acute paraplegia and pulmonary edema after benzathine penicillin injection. Am J Emerg Med 2008;26:250.e1-250.e5.

36. RHDAustralia. Administering Bicillin: reducing pain, stress and inconvenience experienced by patients who need $3-4$ Weekly Im Bicillin La, 2016. Available: 
https://www.rhdaustralia.org.au/resources/administering-bicillin-reducing-pain-stressand-inconvenience-experienced-patients-who

37. Zeydi AE, Khezri HD. Can lidocaine be safely used to reduce pain caused by intramuscular penicillin injections? A short literature review. Oman Med I 2012;27.

38. Hopkins U, Arias C. Large-volume Im injections: a review of best practices. Oncology Nurse Advisor 2013

39. Markowitz M, Lue HC. Allergic reactions in rheumatic fever patients on long-term benzathine penicillin $\mathrm{G}$ : the role of skin testing for penicillin allergy. Pediatrics 1996:97:981-3.

40. Spartalis M, Tzatzaki E, Spartalis E, et al. Mitral valve prolapse: an underestimated cause of sudden cardiac death-a current review of the literature. J Thorac Dis 2017:9:5390-8
41. Rathakrishnan Ssundaram, Gopalan R, Kaliappan T. All breathlessness in mitral stenosis is not pulmonary Edema- a case of mitral stenosis with cardio respiratory arrest. J Cardiovasc Dis Res 2014;5:57-9.

42. Olsson S, Pal SN, Stergachis A, et al. Pharmacovigilance activities in 55 low- and middle-income countries: a questionnaire-based analysis. Drug Saf 2010;33:689-703.

43. DiehI AM, Hamilton TR, Keeling IC. Long-acting Repository penicillin in prophylaxis of recurrent rheumatic fever. J Am Med Assoc 1954;155:1466-70.

44. WHO. Rheumatic fever and rheumatic heart disease. Geneva, Switzerland WHO Technical Report Series 923, World Health Organization; 2001. 